\title{
SAFETY EVALUATION ON THE DEPRESSURIZATION ACCIDENT IN THE GAS TURBINE HIGH TEMPERATURE REACTOR (GTHTR300)
}

\author{
Shoji Katanishi* \\ Japan Atomic Energy Research Institute \\ * Oarai-machi, Ibaraki-ken, 311-1394, Japan \\ Phone: 029-266-7893, Fax: 029-266-7710 \\ E-mail: katanishi@spa.oarai.jaeri.go.jp
}

Kazuhiko Kunitomi

Japan Atomic Energy Research Institute

\begin{abstract}
Japan Atomic Energy Research Institute has been developing a Gas Turbine High Temperature Reactor (GTHTR300) with electric power of approximately 300MW. One of the unique safety design concepts of this system is that events with frequency of occurrence of higher than $10^{-8} /$ reactor-year are evaluated as design basis events in order to show that the frequency of large amount of FP release is less than $10^{-8} /$ reactor-year. According to this concept, a depressurization accident by a large break of helium piping is postulated as a design basis event. This accident is one of the most serious accidents in the high temperature gas-cooled reactors from the view point of loss of coolability. The safety evaluation on the accident was conducted. The short term and long term behaviors of fuel temperature after occurrence of the accident, internal pressure of the reactor building, oxidation behavior of fuels and graphite structures were evaluated and exposure dose of general public was also estimated using the results of evaluation of fuel temperature and fuel failure by oxidation. All of the evaluation results meet the safety criteria and feasibility of the GTHTR300 was clarified by the safety evaluation based on the actual design of the system.
\end{abstract}

Keywords : High temperature gas-cooled reactor, Safety evaluation, Depressurization accident, Gas turbine 


\section{INTRODUCTION}

Japan Atomic Energy Research Institute (JAERI) has been developing a design study on the Gas Turbine High Temperature Reactor (GTHTR300) with electric power of approximately 300MW (Kunitomi, 2002). One of the unique features of safety design of this system is that this system adopts only the passive safety function, such as passive and indirect core cooling system and confinement function of reactor building instead of containment vessel. Another unique safety feature is that the events with frequency of occurrence of higher than $10^{-8} /$ reactor-year are evaluated as design basis events. It can be considered that frequency of occurrence of severe damage of reactor core in a light water reactor is less than approximately $10^{-6} /$ reactor-year and that a large amount FP release has a margin of two digit by the adoption of containment vessel and by accident management. In this point of view, it can be considered that the GTHTR300 is severe-accident-free if the frequency of large amount of FP release is less than $10^{-8} /$ reactor-year. According to this concept, a depressurization accident by simultaneous break of inner and outer pipes of coaxial double piping for helium gas is postulated as a design basis event in the GTHRT300 (Katanishi, 2003). Safety evaluation on the depressurization accident was conducted in order to show that a large amount of fission product (FP) release does not occur and to clarify the propriety of the safety design of this system.

\section{POSTULATED SEQUENCE OF DEPRESSURIZATION ACCIDENT}

Plant layout of the GTHTR300 is shown in Fig.1. Depressurization accident is the most important and characteristic accident of a high temperature gas-cooled reactors (HTGRs). In this accident, increase of fuel temperature due to loss of forced cooling, increase of internal pressure in reactor building by blow-out of high pressure helium gas, oxidation of fuels and graphite core structures due to air ingress into reactor core and exposure of public by FP release are potentially postulated. Each of these items were evaluated under the conservative assumptions as safety evaluation.

Postulated sequence of depressurization accident is shown in Fig.2. Sequence and items to be evaluated are as flows:

(1) the simultaneous break of inner and outer pipes of coaxial double piping for helium flow,

(2) blow-out of high pressure helium gas into a reactor building,

(3) release of helium gas into environment from pressure release stack by the opening of blow-out panels,

- capability of reactor shutdown,

- fuel integrity against fuel temperature increase

- integrity of reactor building against pressure increase

- public dose by FPs released with blow-out of helium gas (release of FPs contained within primary system during normal operation)

(4) closing of airtight closure to prevent oxidation of fuels and core materials by air ingress from environment,

(5) long-term cooling of reactor core by the vessel cooling system (VCS) which is a fully passive system using natural circulation of air and installed at the outside of the reactor pressure vessel (RPV), as shown in Fig.3 (Katanishi, 2004). 
- fuel failure by oxidation

- integrity of graphite core structures against oxidation in the view point of maintaining of coolable geometry and prevention of recriticality

- public dose by long term FP release which are released additionally by fuel failure due to oxidation and by diffusion through coating layers of coated fuel particles (CFPs) according to temperature increase

\section{FUEL TEMPERATURE BEHAVIOR}

Reactor kinetics and transient behavior of temperature and pressure during short term after occurrence of depressurization accident were evaluated by using a dynamic characteristic evaluation code for the GTHTR300 (Takamatsu, 2004). This code was developed for safety evaluation of the GTHTR300 based on RELAP5/MOD3 code. Three different pipe break positions, between RPV and power conversion vessel (PCV), between PCV and heat exchanger vessel (HXV) and between RPV and HXV, were postulated in the evaluation. The one point reactor kinetics, thermal hydraulics of helium gas of coolant, dynamic characteristics of turbomachinery, behavior of control systems of reactor and turbomachinery are evaluated by this code. The heat transfer in reactor core, in double piping, in heat exchangers, in RPV and cooling panels of the VCS are also evaluated in this code. By the analysis using this code, it was shown that the fuel temperature becomes the highest in case of the pipe break between RPV and PCV, and that the maximum fuel temperature is 1422degree-C which is lower than the criteria for fuel failure (1600 degree-C) even in this case. It was clarified in this evaluation that the reactor is scrammed by scram signal of "low coolant pressure" and that no fuel failure occurs during short term after the depressurization accident.

After loss of forced cooling and reactor scram in depressurization accident, air enters inside of the primary system from ruptured opening of piping. The natural circulation of mixture gas of air and helium occurs in the inside of primary system including reactor core. The residual heat in the reactor core is removed mainly by the VCS at the outside of the RPV. It is transferred from the core structures to the RPV by conduction of heat and radiation, then, removed by the radiation and natural circulation of air in the outside of the RPV to environment through the cooling panels of the VCS. Flow rate of the natural circulation and behavior of heat transfer and temperatures in this system were evaluated by using TAC-NC code which is to calculate the transient behavior of the natural circulation and the temperature distribution. TAC-NC code was used in the safety evaluation of the High Temperature Engineering Test Reactor (HTTR) of JAERI and was already validated by the results of experiments simulating air ingress accident (Kunitomi, 1989). All of the components, such as reactor core, the RPV, cooling panels of the VCS in the outside of the RPV and air inlet and outlet of VCS in the outside of reactor building, were modeled in the TAC-NC code. The long term behavior of temperature and the heat transfer by radiation and natural circulation in each part were calculated by this code. In the calculation result, the fuel temperature has the maximum value at the 70hours after occurrence of depressurization accident. However, it is lower than 1600 degree-C, as shown in Fig.4.

From these evaluation results, it was clarified that the fuel temperature is kept to be lower than the 
criteria by the heat removal through the VCS and that the additional fuel failure does not occur by the the temperature increase in depressurization accident.

\section{INTEGRITY OF REACTOR BUILDING AGAINST PRESSURE INCREASE}

A containment vessel which has tight leak-resistance and pressure-resistance is not installed in the GTHTR300. A reactor building of the GTHTR300 has a confinement function to mitigate air ingress from environment and FP release to environment. When the large break of pressure boundary of primary system occurs, high pressure might be applied to the inside of the building until pressure is released through the pressure release stack to the environment by opening of blow-out panels. Integrity of reactor building in the depressurization accident was evaluated in the view point of increase of building internal pressure and temperature. Inside of the building is divided into some compartments. In the evaluation, six different pipe break positions were postulated as shown in Fig.5. Since each wall between any compartments has an opening for pressure release, the blow-out helium gas spreads into every compartment before it is released to environment through pressure release stack.

Transient behavior of the temperature and pressure in each compartment of the reactor building was calculated with the simultaneous equations of state of gas, the mass balance equation, the heat balance equation and the gas velocity equation for critical flow and sub-critical flow.

Evaluation results are summarized in Table 1. In each case, the compartment in which pipe rupture occurs has the highest pressure. Especially, the peak pressure in the compartment of the reactor pressure vessel was evaluated to be approximately $1.3 \mathrm{MPa}$ that is the highest pressure in all cases. However, this compartment is designed under the pressure condition of higher than 1.3MPa. Furthermore, building internal pressure reaches peak value at 0.1 to 0.2 seconds after depressurization occurs, and decreases rapidly during short time. By these evaluation results it was shown that the integrity of the building can be maintained under the depressurization accident condition. The gas temperature in each compartment was evaluated to be the highest in case of pipe rupture in the compartments of reactor pressure vessel, heat exchanger vessel or lower coaxial piping. The maximum temperature is approximately 260degree-C in each case. The temperature of the concrete wall in each compartment was also evaluated. However, since the heat capacity of concrete wall is larger enough than that of helium gas, the temperature increase is only a few degree-C and integrity of concrete wall can be maintained.

\section{OXIDATION BEHAVIOR OF FUEL AND GRAPHITE CORE STRUCTURES}

Oxidation of fuel and graphite core structures were evaluated by using the calculation results of long term temperature behavior and flow rate of natural circulation of air after air ingress from ruptured opening of double piping occurs. Time history of oxidation distribution in the reactor core was evaluated by using the GRACE code (Kawakami, 1986). This code calculates the three processes, that is, mass transport from air to boundary layer of graphite surface, diffusion of oxygen from graphite surface to the inside of matrix in a graphite block and chemical reaction of oxygen and graphite. Distribution of oxygen concentration along air flow is calculated by mass conservation equation with consideration of diffusion of oxygen into graphite block. 
Enlargement of flow area by oxidation is also taken into account. This code was used in safety evaluation of the HTTR and already validated by results of oxidation experiments simulating a flow path in graphite block and a fuel pin.

Natural circulation nearby the ruptured opening of double piping was calculated taking into account of pressure loss by the shape of opening under a conservative assumption that helium gas at the inside of pressure boundary had been fully replaced by air. Oxygen concentration of the air in the inside of the building, that entered the inside of the primary system, was calculated by the difference of gas composition between inside and outside of the reactor building. In the inside of the building, there is a much quantity of $\mathrm{CO}$ and $\mathrm{CO}_{2}$ which are produced by oxidation of graphite in the reactor core. Because these gases are heavier than the air in the outside of the building, they leaks to outside through the lower part of building wall according to the leak rate of the building. On the other hand, air enters the inside of the building through upper part of the wall, as shown in Fig.6. The time history of changing of gas composition in the building by replacement of air and internal gases due to this process was calculated according to conservative value of leak rate of the building that was $20 \% / d$ under the pressure difference of $10 \mathrm{mmAq}$. The oxidation of graphite in the reactor core was calculated with these gas composition by using the GRACE code.

Quantity of fuel failure by oxidation was evaluated based on the oxidation condition of each position of fuel region for the purpose of calculation of the FP release to the environment. CFPs of the GTHTR300 have a $\mathrm{SiC}$ coating layer to contain FPs, as shown in Fig.7. If the $\mathrm{SiC}$ layer is oxidized under lower temperature or high oxygen concentration condition, stable $\mathrm{SiO}_{2}$ layer is formed and oxidation is suppressed by the stable layer covering the fuel kernel of CFP. The integrity of SiC coating layer is kept and the FP release can be prevented in this case. On the other hand, if $\mathrm{SiC}$ layer is oxidized under high temperature or low oxygen concentration condition, the unstable $\mathrm{SiO}$ is formed and corrosion of $\mathrm{SiC}$ layer by oxidation will progress. In the latter case, $\mathrm{FP}$ can be release to the outside of CFPs. In the evaluation, fuel failure by oxidation was judged based on the formation of unstable $\mathrm{SiO}$ on the $\mathrm{SiC}$ coating layer. If temperature and oxygen concentration in each position which were calculated by the GRACE code were judged to be in the condition of SiO formation based on the criteria shown in Fig.8, the CFPs in that position were assumed to fail by oxidation.

By the evaluation, it was clarified that fuel failure fraction is the highest at the bottom part of the fuel region of the core, and that the oxidation is stopped after certain time proceeds because condition in that position changes to be out of the region for formation of $\mathrm{SiO}$, as shown in Fig.9. The average fraction of failed CFPs in the whole core was calculated to be less than $5 \times 10^{-3} \%$.

In case of air ingress into the reactor core, not only fuel but also graphite structure of core is oxidized. The integrity of graphite support plate for fuel rod was discussed from the calculated oxidation distribution in the reactor core by GRACE code. The maximum equivalent decrease of thickness of support plate was calculated to be $1.9 \mathrm{~mm}$. It was clarified that structural integrity of fuel support can be maintained even in case of air ingress by depressurization accident and the coolable geometry of fuel rod can be kept.

\section{PUBLIC EXPOSURE DOSE}


Public exposure dose by FP release during depressurization accident was evaluated with the assumption of the same siting condition as the HTTR. As for source term, release of the following FPs were postulated; the additional FP release from failed fuel by the oxidation, the additional FP release from CFPs by diffusion through coating layers according to temperature increase and the release of FPs which was existing in the primary system from the time of fuel loading due to initial failure of CFPs. A fraction of initial fuel failure was conservatively assumed to be $5 \times 10^{-2} \%$. A part of these FPs in primary system is circulating with helium gas and another part is plated-out on the inner surface of primary system.

In the short term after depressurization accident occurs, $100 \%$ of the circulating FPs and $60 \%$ of plated-out iodine at the primary system were assumed to be released into environment with blow-out helium gas from the pressure release stack with height of $60 \mathrm{~m}$ from ground level.

As for the long term FP release, FPs released from oxidized fuel particle and released by diffusion through coating layers with temperature increase by decay heat after loss of forced cooling were taken into account. The additional FP release with fuel failure by oxidation was calculated from the above mentioned results of the oxidation. FP release by diffusion through the coating layers was calculated by using the time history of temperature obtained by the TAC-NC code. These FPs were assumed to be released into environment from the ground level according to the leak rate of reactor building. Plate-out of FPs on the inner surface of confinement wall of reactor building was also taken into account.

Evaluated effective dose are listed in Table 2. An effective dose for infant was evaluated to be $4.7 \mathrm{mSv}$. The all of the evaluated dose meet with the reference criteria value of $5 \mathrm{mSv}$ for public dose that means these is no serious exposure risk on general public.

\section{CONCLUSIONS}

Safety evaluation on the depressurization accident which is the most severe event in the view point of decrease of cooing capability was carried out. It was certified that every safety function can be maintained and there is no serious risk to the general public. The feasibility of the GTHTR300 are clarified through these evaluation based on the actual design of GTHTR300. It is concluded that the GTHTR300 is a severe-accident-free system because the large amount of FP release does not occur in the most serious accident such as depressurization accident only by the passive safety functions and without a containment vessel nor any accident management.

\section{References}

[1] Kunitomi, K., et al., 2002, Trans. At. Energy Soc. Japan, Vol. 1, pp 352-360 (in Japanese)

[2] Katanishi, S., et al., 2003, Trans. At. Energy Soc. Japan, Vol. 2, pp 55-67 (in Japanese)

[3] Katanishi, S., et al., 2004, Trans. At. Energy Soc. Japan, Vol. 3, pp 257-267 (in Japanese)

[4] Takamatsu, K., et al., 2004, Trans. At. Energy Soc. Japan, Vol. 3, pp 76-87 (in Japanese)

[5] Kunitomi, K., et al., 1989, JAERI-M 89-001 (in Japanese)

[6] Kawakami, H., Tanso, 1986 (No.124), 26 
Table 1 Evaluation results of internal pressure and temperature in the reactor building

\begin{tabular}{|l|c|c|}
\hline \multicolumn{1}{|c|}{ Position of pipe break } & $\begin{array}{c}\text { Peak pressure } \\
\text { (MPa) }\end{array}$ & $\begin{array}{c}\text { Peak temperature } \\
\text { (degree-C) }\end{array}$ \\
\hline Compartment of power conversion vessel & 0.27 & 190 \\
\hline Compartment of heat exchanger vessel & 0.50 & 260 \\
\hline Compartment of lower coaxial pipe & 0.56 & 260 \\
\hline $\begin{array}{l}\text { Compartment of reactor pressure vessel } \\
\text { (break of pipe to power conversion vessel) }\end{array}$ & 1.30 & 260 \\
\hline $\begin{array}{l}\text { Compartment of reactor pressure vessel } \\
\text { (break of pipe to heat exchanger vessel) }\end{array}$ & 1.22 & 260 \\
\hline
\end{tabular}

Table 2 Evaluated effective dose by the depressurization accident

\begin{tabular}{|l|c|}
\hline \multicolumn{1}{|c|}{ Item } & $\begin{array}{c}\text { Evaluation result } \\
(\mathrm{mSv})\end{array}$ \\
\hline Effective dose for infant & 4.7 \\
\hline Effective dose by external exposure & 0.0045 \\
\hline External exposure by sky shine $\gamma$ ray & 0.0012 \\
\hline
\end{tabular}

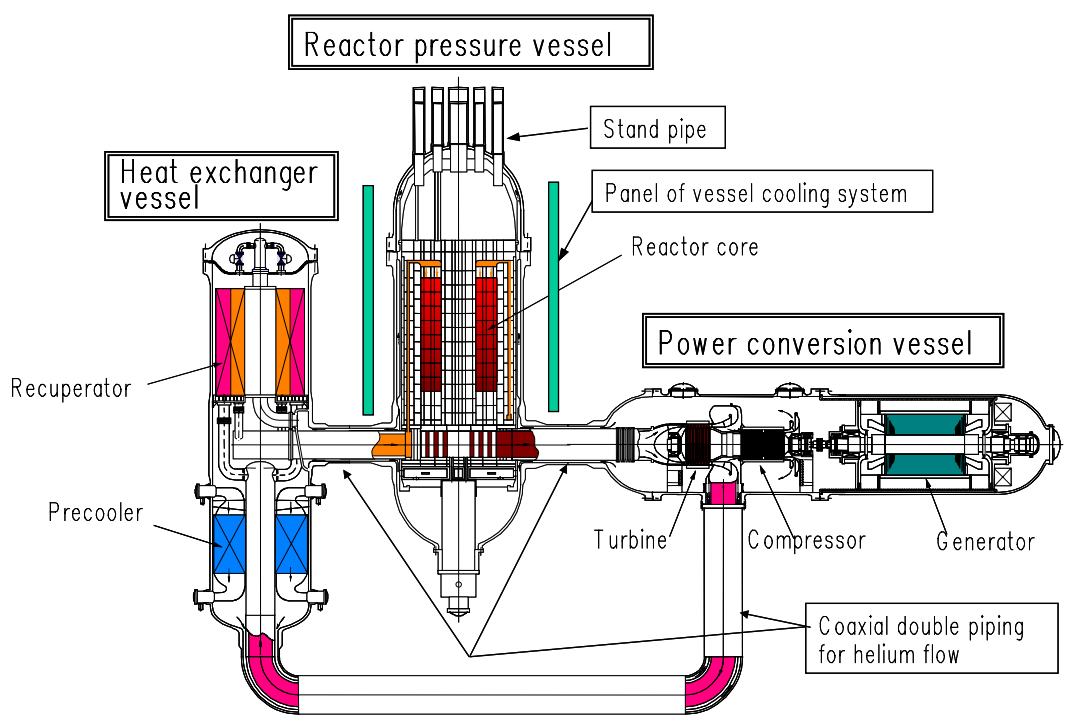

Fig.1 Plant layout of the GTHTR300 


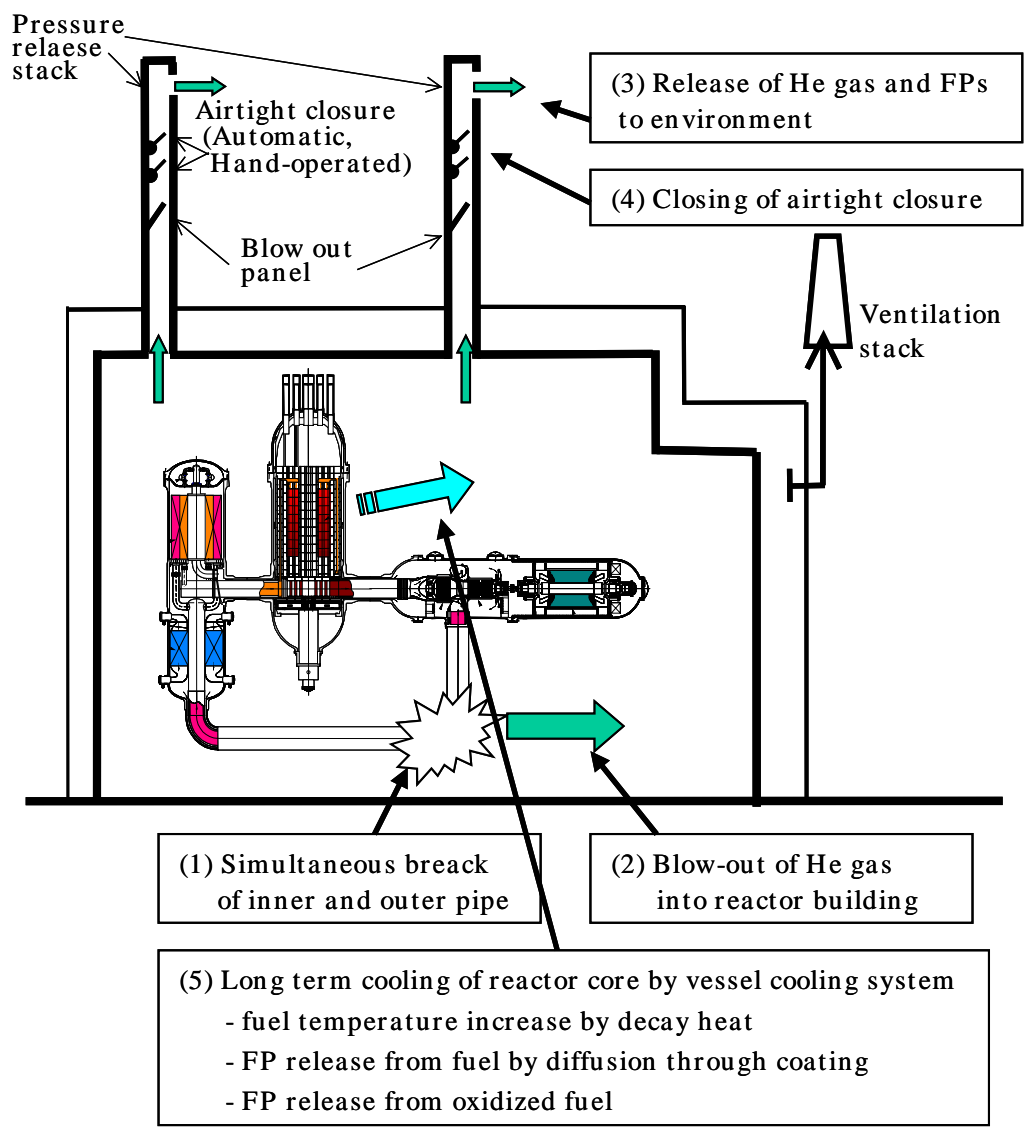

Fig.2 Postulated sequence in the depressurization accident

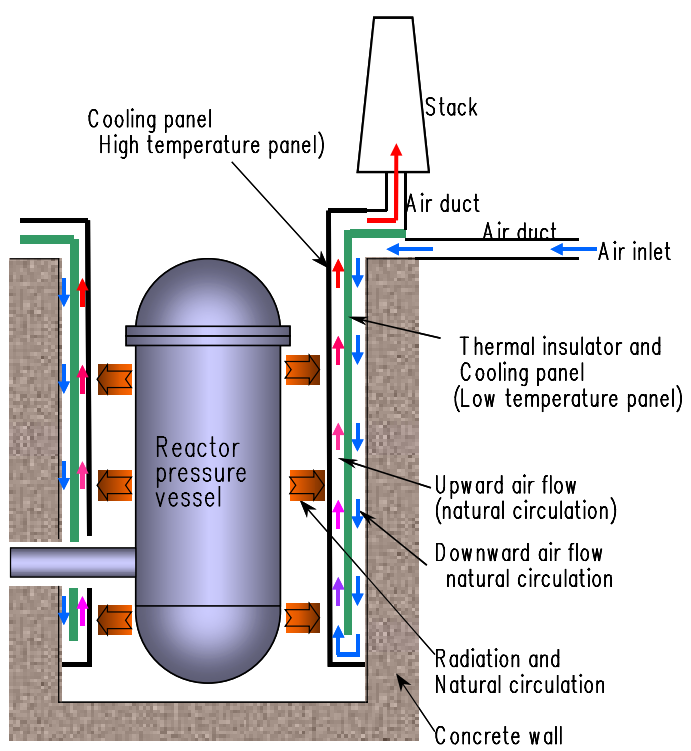

Fig.3 Outline of vessel cooling system

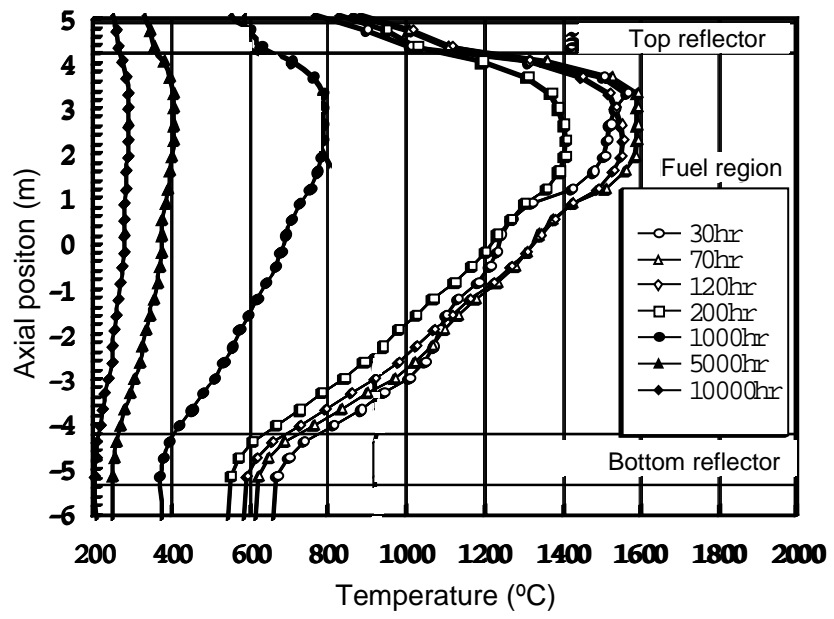

Fig.4 Calculated long term temperature behavior 


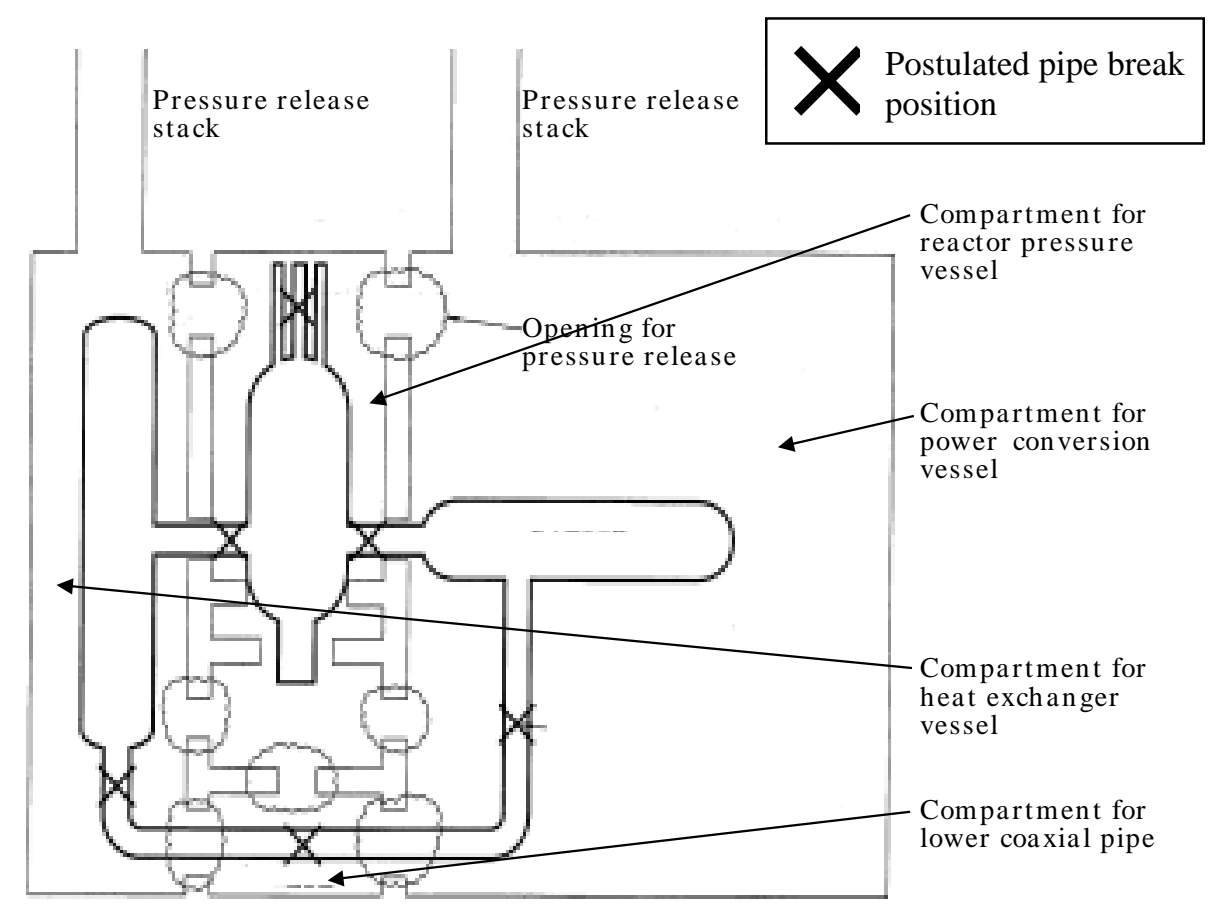

Fig.5 Postulated position of pipe break

Confinement :

leak rate: $20 \% / d$ under pressure difference of $10 \mathrm{mmAq}$

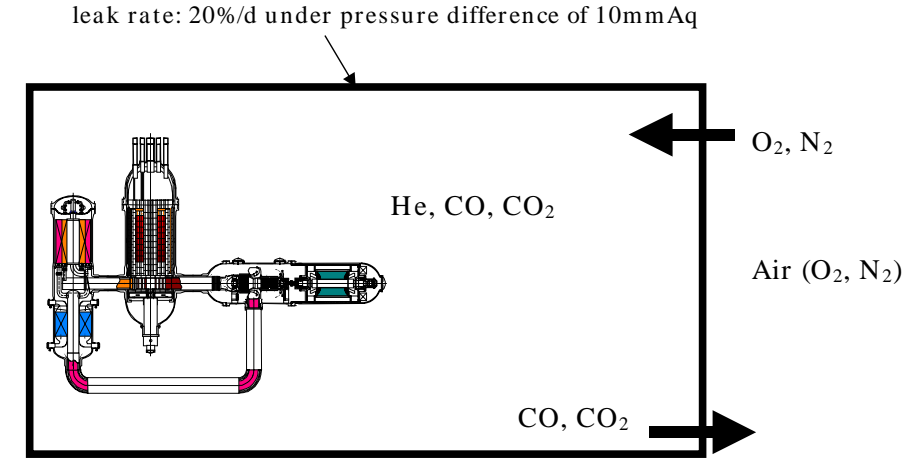

Leak rate : $20 \% / \mathrm{d}$ (under pressure difference of $10 \mathrm{~mm} \mathrm{Aq}$ )

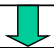

Gases in the inside and outside of confinement are replaced

with the leak rate of $20(\% / \mathrm{d}) \times \Delta \mathrm{P}(\mathrm{mmAq}) / 10(\mathrm{mmAq})$

Fig.6 Calculation model of gas composition in reactor building 


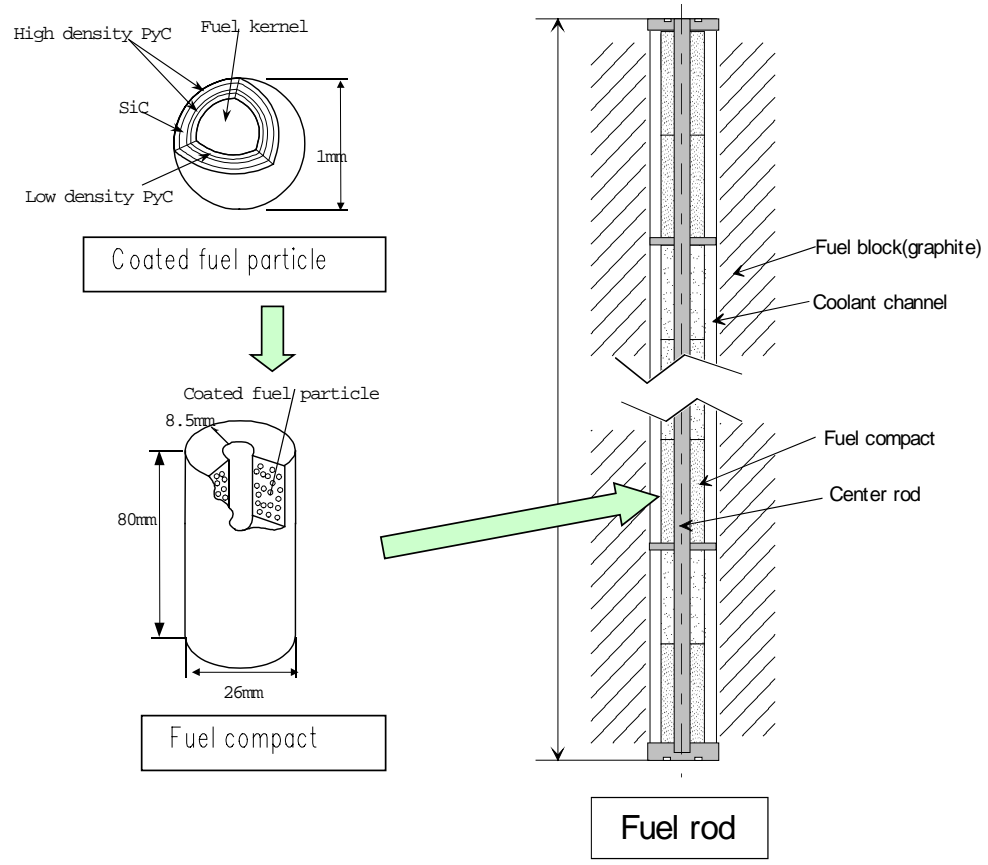

Fig.7 Schematic drawing of CFP and Fuel rod in the GTHTR300

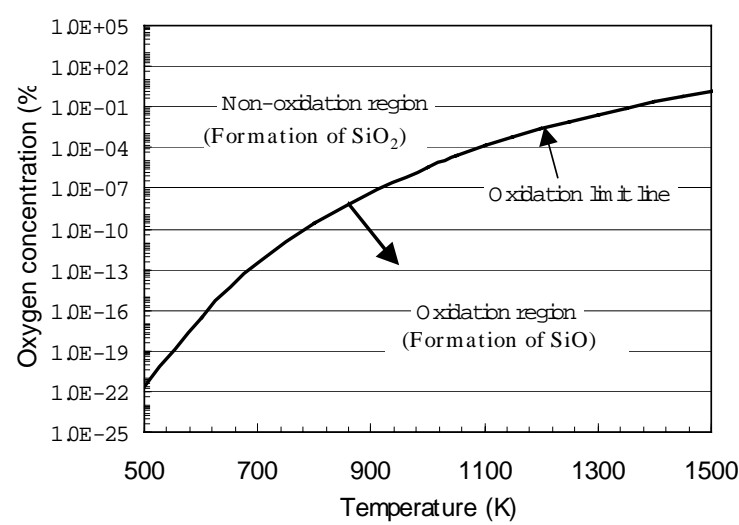

Fig.8 Criteria for condition of unstabel SiO formation in coated fuel particles

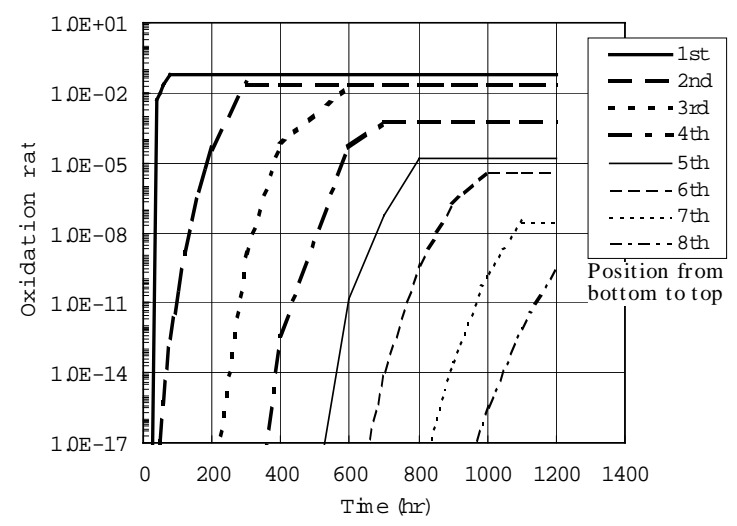

Fig.9 Calculated fuel failure fraction by oxidation 